\title{
MONITORING TIANJIN LAND SUBSIDENCE BY SBAS-INSAR BASED ON SENTINEL-1A SAR IMAGES
}

\author{
Zilin $\mathrm{ZHU}^{1}$, Chao REN ${ }^{1,2}$, Lv ZHOU ${ }^{1,3}$ * , Xianjian SHI ${ }^{1}$, Xianguang $\mathrm{LI}^{1}$, Di Zhang ${ }^{4}$ \\ ${ }^{1}$ College of Geomatics and Geoinformation, Guilin University of Technology, Guilin China - zhuzilin@glut.edu.cn \\ ${ }^{2}$ Guangxi Key Laboratory of Spatial Information and Geomatics, Guilin China - renchao@glut.edu.cn \\ ${ }^{3}$ Key Laboratory of Geospace Environment and Geodesy, Ministry of Education, Wuhan University, Wuhan China - \\ zhoulv_whu@163.com \\ ${ }^{4}$ School of Geodesy and Geomatics, Wuhan University, Wuhan, China - zhangdi@whu.edu.cn
}

KEY WORDS: SBAS-InSAR, times characteristics, land subsidence, Tianjin area

\begin{abstract}
:
In order to understand the spatial-temporal evolution of land subsidence in Tianjin, in this study, we applied the Small Baseline Subset Interferometric Synthetic Aperture Radar (SBAS-InSAR) technique to process 36 Sentinel-1A images acquired between 2015 and 2018 released by European Space Agency (ESA). The results show that during the study period, most of the regional land subsidence rate in study area ranged from -18 to $9 \mathrm{~mm} / \mathrm{a}$ from 2015 to 2018, and the maximum subsidence rate exceeded $75 \mathrm{~mm} / \mathrm{a}$, the largest subsidence center is located in Wang qingtuo Town, Xiqing District, Tianjin. Furthermore, the SBAS-InSAR-derived result was verified by levelling data. The alignment was relatively high, and the maximum and minimum deviation were $6.4 \mathrm{~mm}$ and $3.3 \mathrm{~mm}$, respectively, demonstrating that the SBAS-InSAR technique is feasible to monitor land subsidence in Tianjin area. The main influencing factors with respect to subsidence show different depending on different region. Additionally, the severe land subsidence in Tianjin is mainly caused by rapid urban development and urban surface load increase.
\end{abstract}

\section{INTRODUCTION}

Urban land subsidence is a slow regional geological disaster caused by natural geological disasters (such as earthquakes, volcanoes, etc.) or human activities (such as groundwater exploitation, building loads, etc.), for urban construction, agricultural development, flood control and drainage, seriously affecting people' s lives and property (Zhao, et al, 2009; RuizConstán A, et al, 2016; Gao, et al, 2019). Therefore, it is very important to strengthen the monitoring of land subsidence. At present, for the monitoring and analysis of land subsidence, the traditional monitoring methods mainly include leveling, GPS measurement, monitoring targets (base rock standard and layered standard group) and so on, which can obtain higher time resolution and higher precision of the study area. Variable (Yin, et al, 2011), but the spatial resolution is low, it is difficult to effectively analyze the deformation within the entire study range. The conventional differential interferometric synthetic aperture radar (DInSAR) has become an internationally recognized effective method for land subsidence monitoring because of its high spatial resolution in surface settlement monitoring (Dong, et al, 2013; Amelung F, et al, 1999). However, due to the effects of spatial decoherence and atmospheric delay, the accuracy and reliability of traditional DInSAR technology will be reduced in the application process, in order to reduce the above effects, the small baseline subset interferometric synthetic aperture radar (SBAS-InSAR) technology is a new technology based on the conventional DInSAR, this technology not only limits the loss of time and space, improves the utilization of images, but also enriches the observation information of images (Berardino P, et al, 2002; Wu, et al, 2017). In this paper, 36 Sentinel-1A data from 2015 to 2018 were used to monitor the land subsidence in Tianjin by SBAS-InSAR technology. The distribution of subsidence and deformation rate in Tianjin were obtained. The feasibility of monitoring urban land subsidence by SBAS-InSAR technology was verified by comparing with the second-class leveling data in Tianjin. The relationship between the spatial and temporal variation of subsidence and the development of groundwater and urbanization is discussed and analyzed in order to provide theoretical support for grasping the surface deformation of Tianjin area.

\section{SBAS-INSAR TECHNIQUE PRINCIPLE}

SBAS-InSAR is a time series InSAR analysis method proposed by Bernardino et al (Zhou, et al, 2016). This method mainly performs the correlation arrangement and combination of the obtained data to obtain the spatial baseline differential interferogram, which can better overcome the decoherence phenomenon. The SBAS-InSAR technique mainly uses the singular value decomposition method or the least squares method to calculate the deformation rate of the study area, and can also connect the SAR data sets separated by the larger spatial baseline to increase the sampling rate of the observation data. The main steps are as follows (Sun, et al, 2016):

1. During $\left(\mathrm{t}_{0}, \mathrm{t}_{1}, \cdots, \mathrm{t}_{\mathrm{n}}\right)$ time, select the scene image as the super master image and register the other remaining slave images to the Sentinel-1A image data of the same $(\mathrm{N}+1)$ scene. Assuming that at least one scene image interferes with each scene image, the $(\mathrm{N}+1)$ scene image generates a M-view differential interferogram, and $\mathrm{M}$ satisfies the condition.

$$
(N+1) / 2 \leqslant M \leqslant N(N+1) / 2
$$

2. The interference phase of the $j$ th scene difference interferogram generated by the image obtained at the time of the remaining slave image $t_{A}$ and the time of the super

\footnotetext{
* Corresponding author : zhoulv_whu@163.com
} 
master image $t_{B}\left(t_{B}>t_{A}\right)$ (ignoring the influence of the atmospheric delay phase, the residual topography phase, and the noise phase) can be expressed as:

$\delta \phi_{j}=\phi_{B}(x, r)-\phi_{A}(x, r) \approx \frac{4 \pi}{\lambda}\left[d\left(t_{B}, x, r\right)-d\left(t_{A}, x, r\right)\right]$

In the formula: $\phi$ is the interference phase; $j$ is the sign of the differential interferogram, $j \in(1, \cdots, M)$; $\lambda$ is the center wavelength of the signal; $d\left(t_{A}, x, r\right)$ and $d\left(t_{B}, x, r\right)$ are the cumulative deformations in the line-of-sight direction of $t_{A}$ time and $t_{B}$ time relative to $d\left(t_{0}, x, r\right)=0$ respectively.

3. The interference phase in ( 2 ) can be expressed as the product of average phase velocity $v_{j}$ and time in two acquisition times.

$$
v_{j}=\left(\phi_{j}-\phi_{j-1}\right) /\left(t_{j}-t_{j-1}\right)
$$

Then the phase value of the $j$ th scene interferogram is

$$
\sum_{k=t_{A, j}, 1}^{t_{B}, j}\left(t_{k}-t_{k-1}\right) v_{k}=\delta \phi_{j}
$$

That is to say, the integral of velocity in each time period on the super master image time interval and the remaining slave image time interval is expressed in the form of a matrix.

$$
B \nu=\delta \phi
$$

In the process of calculating the coefficient matrix $B$, because the SBAS-InSAR technique uses multi-master image method to obtain differential interferogram, the matrix $B$ may appear rank deficit. The generalized inverse matrix $B$ of the matrix can be solved by the singular value decomposition method (SVD) to obtain the minimum norm solution of the velocity vector. Finally, the shape variables in each time period are obtained by integrating the velocity of each time segment.

\section{SURVEY AND DATA OF STUDY AREA}

In recent years, with the rapid development of urban and rail transit construction in Tianjin, a complete transportation network has been basically formed, and new settlement centers are constantly emerging. In order to further study the land subsidence in Tianjin, this paper studied the urban area of Tianjin using entinel-1A data under the regional selection mode. As shown in Figure 1, the experimental data are tailored to obtain the scope of this paper.

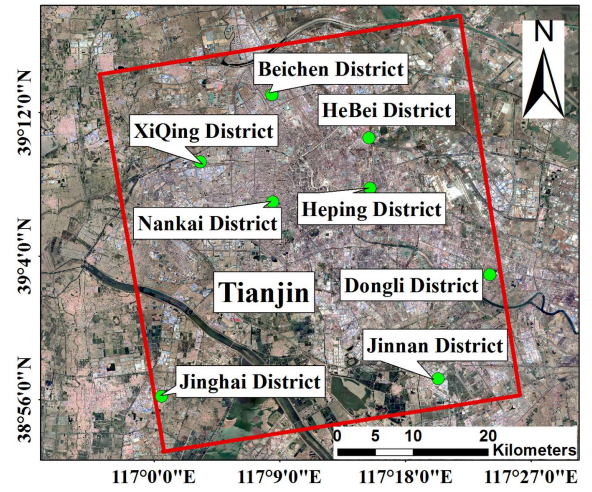

Figure 1. Geographical extent of the study area

In this paper, 36 images of Sentinel-1A are obtained from ESA during the period of 2015-08-23 to 2018-10-06. The incident angle is 39.5 degrees and the wavelength is $5.6 \mathrm{~cm}$. The observation mode is interference wide-band (IW) and the polarization mode is $\mathrm{VH}$ polarization. The main application mode of Sentinel-1A is interference width (IW), which is also the main mode of monitoring land subsidence. At present, most of the requirements for SAR can be basically satisfied. In this study, the revised orbit parameters (AUX_RESORB, POD Restituted Orbit) provided by ESA are used to remove the leveling effect and track refinement. The revised orbit parameters are generated within 21 days from Sentinel-1 data acquisition and are within $5 \mathrm{~cm}$ of the track parameters file $(\mathrm{Li}$, et al, 2018; Zhang, et al, 2017). In addition, the SRTM V4 DEM provided by the US NASA used in the data processing process removes the terrain phase.

\section{DATA PROCESSING AND RESULT ANALYSIS}

\subsection{Data processing}

This research mainly used SARscape data processing software and 36 Sentinel-1A image data to monitor the land subsidence in Tianjin from 2015 to 2018 . The main processing flows are as follows:

1. Data preprocessing: Pre-processing the 36 scenes original Sentinel-1A image data, and obtaining the study area by cutting;

2. Generate baseline pairs: we selected the images acquired on April 14, 2017 as the super master image, and all the remaining slave images were registered to the super master image, and 441 pairs of interferograms were generated (Figure 2). The green dots in Figure 2 represent SAR images, line segments represent interferograms, and yellow dot denotes the super master image;

3. Interferometric work and phase unwrapping: interferometric processing was performed on 441 image pairs, and a phase unwrapping diagram was finally generated;

4. Orbital refinement: This step was mainly used to remove the residual phase that does not meet the requirements and the ramp phase that still exists after unwinding;

5. The time series results retrieval: the singular value decomposition method was used to calculate the deformation phase after unwrapping, and then the deformation rate in each period was obtained. Finally, the shape variable in the line of sight direction (LOS) of each time period is obtained by geocoding (negative value indicates settlement, positive value indicates lift) 


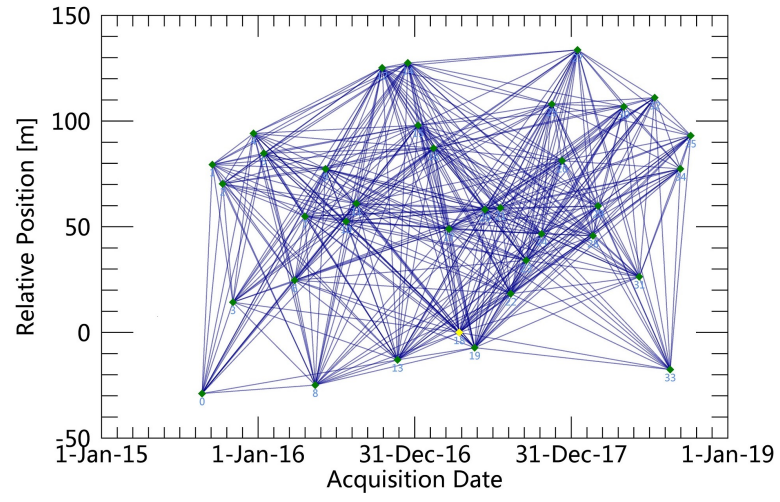

Figure 2. Spatiotemporal baseline distribution

\subsection{Result analysis}

4.2.1 Analysis of settlement rate in research area: This paper studied the monitoring of land subsidence in Tianjin from 2015 to 2018. It can be seen from the ground vertical sedimentation rate map of Tianjin from 2015 to 2018 in Figure 3. During the study period, $90 \%$ of the deformation rates in the study area are in the range of $-18 \mathrm{~mm} / \mathrm{a} \sim 9 \mathrm{~mm} / \mathrm{a}$ (positive values indicate that the surface rises, negative values indicate that the surface decreases). Groundwater exploitation is strictly controlled in the six districts of Tianjin, therefore, the land subsidence is relatively small and stable in the central districts of Tianjin, Heping District, Hedong District, Hebei District and Nankai District, and the subsidence deformation rate in most area is less than $5 \mathrm{~mm} / \mathrm{a}$; there are obvious subsidence funnels in Xiqing district, among which Yuanjiabao village, Youzhangbao village and Qingguang town in Wangqingtuo town have serious subsidence centers, Xiaowangbao industrial zone and Yuanjiabao industrial zone in Wangqingtuo town have the most obvious subsidence, the annual subsidence rate exceeds $75 \mathrm{~mm} / \mathrm{a}$ and the maximum cumulative subsidence reaches $190 \mathrm{~mm}$. The industrialization in this area is developing rapidly, the groundwater exploitation is serious, and the increase of ground load is the main cause of subsidence in this area; the settlement of Yangchengzhuang Township and Daxingdui Township in the study area of Jinghai County research area is more obvious. The annual average settlement rate in this area exceeds $45 \mathrm{~mm} / \mathrm{a}$ and the maximum cumulative settlement reaches $150 \mathrm{~mm}$. In recent years, the urbanization of Jinghai County has developed rapidly, the urban expansion is serious, and the overexploitation of groundwater is the main reason for the settlement in this area; the settlement of Balitai Town and Beizhakou Town in Jinnan research area is the most obvious. The annual average settlement rate is over $30 \mathrm{~mm} / \mathrm{a}$ and the maximum cumulative settlement reaches $90 \mathrm{~mm}$. The main causes of settlement in this area are urbanization expansion and groundwater exploitation.

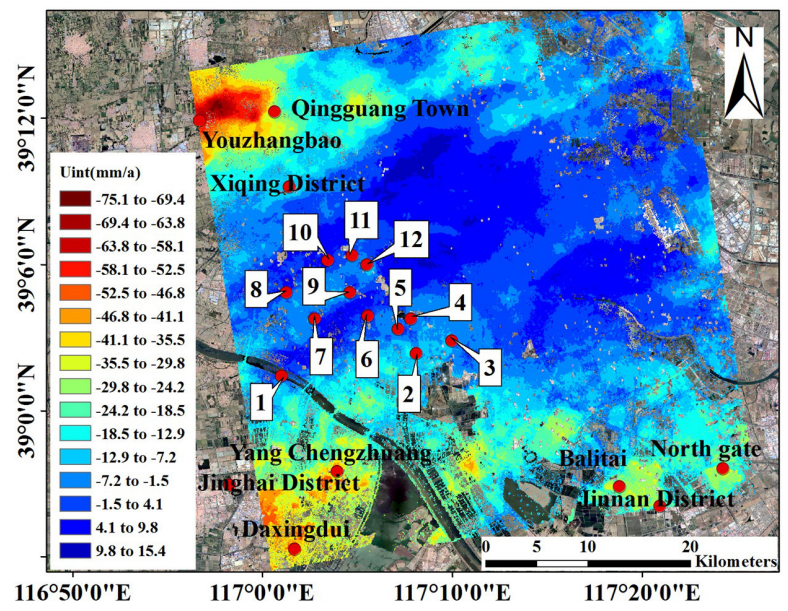

Figure 3. Ground vertical settlement rate in Tianjin from 2015 to 2018 
4.2.2 Accuracy verification analysis: The main subsidence area studied in this paper are Xiqing District, Jinghai County and Jinnan District. The spatial distribution of the results obtained by SBAS-InSAR technology and the maximum settlement area are basically consistent with Guo et al (Guo, et al, 2017). which verifies the reliability of this method to obtain land subsidence and deformation in Tianjin area. In order to further verify the reliability of SBAS-InSAR results based on Sentinel-1A data, this study selected 12 second-level leveling point data in the study area (the level 1-12 distribution is shown in Figure 3) to compare the second-class leveling data with SBAS-InSAR processing results, and the results were shown in Figure 4. As can be seen from Figure 4 that the leveling results agree well with those of SBAS-InSAR processing results; the maximum relative error of the two methods is $6.4 \mathrm{~mm}$, the minimum relative error is $-1.8 \mathrm{~mm}$, and the medium error is $3.17 \mathrm{~mm}$. The above results indicate that SBAS-InSAR method are in good agreement with those second-level leveling data, and the results of this research are highly reliable.

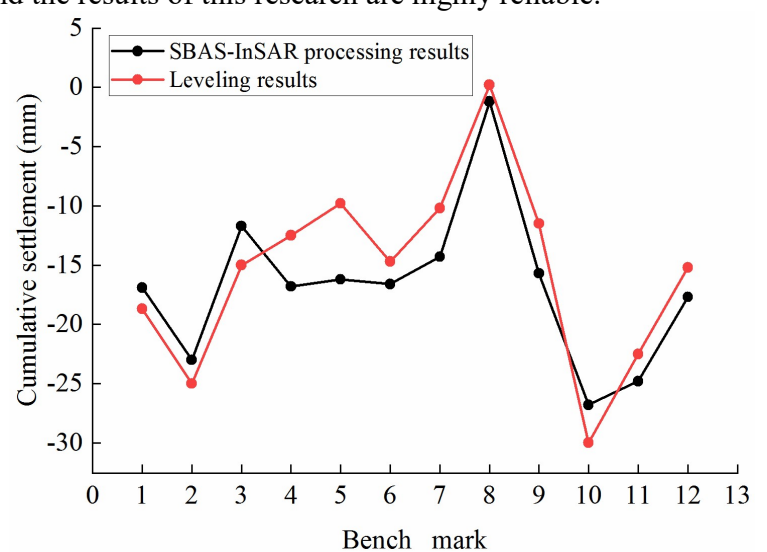

Figure 4. Leveling results and SBAS-InSAR processing results

\subsection{Settlement analysis of industrial zone}

The regional subsidence of Wangqingyu Town and Qingguang Town in Xiqing District is more serious, and there is obvious settlement funnel, and the settlement area has a tendency to extend westward. Figure 5 shows the deformation rate of the settlement area in Xiqing district. Figure 11 shows the land utilization of the subsidence area in Xiqing district. The industrialization of this area is developing rapidly. Wangqingtuo Town is known as the hometown of bicycles in China. More than 200 bicycle factories are gathered here. The underground development is more serious during industrial development. Therefore, land subsidence is affected by factors such as ground loading and over-exploitation of groundwater. It can be found from Fig. 5 and Fig. 6 that the two factories in Yuanjiabao Village and Youzhangbao Village (the triangular area in Fig. 5, the circular area in Fig. 6) are the most severely settled area in this study, and the annual average settlement rate is the largest. The maximum annual average settlement rate is more than $75 \mathrm{~mm} / \mathrm{a}$, and the maximum cumulative settlement is $190 \mathrm{~mm}$. It shows that the larger surface space utilization plays an important role in surface settlement. Compared with the Xiqing subsidence area, the settlement of Jinghai settlement area and Jinnan settlement area is small.

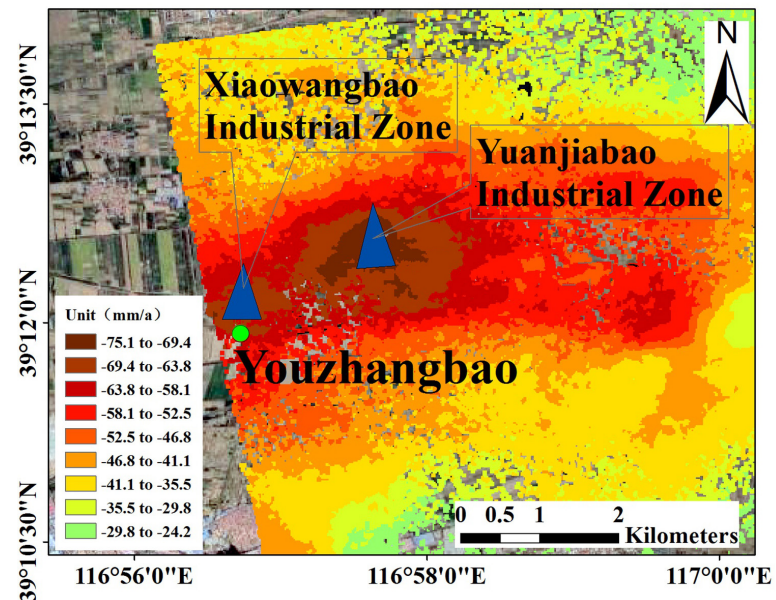

Figure 5. Settlement deformation rate in Xiqing district

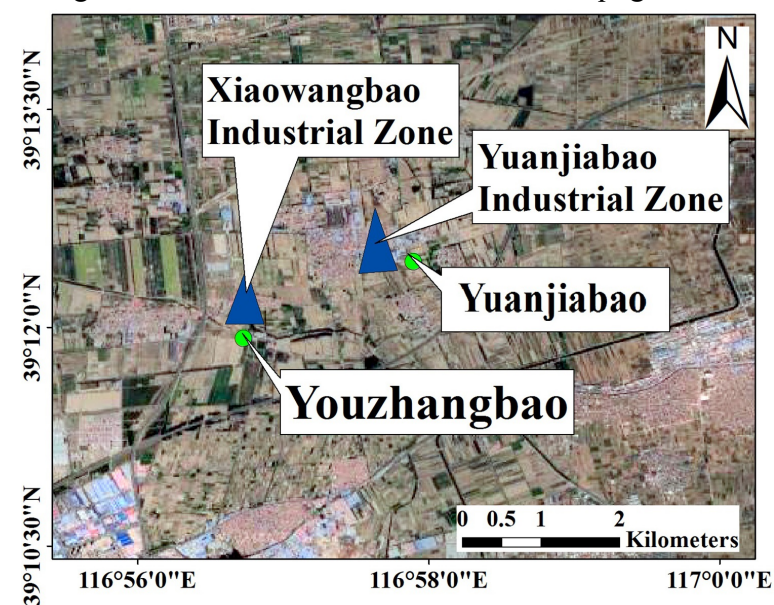

Figure 6. Surface space utilization in Xiqing district During the period from 2015 to 2018, the groundwater level was basically declining due to over-exploitation of groundwater in Xiqing District. At the same time, due to the impact of industrialization and population growth, the urbanization area of Tianjin is gradually increasing, so the land subsidence of Tianjin is becoming more and more serious. The more serious settlement areas such as Qingguang Town and Wangqingyu Town have a tendency to expand westward.

\section{CONCLUSION}

This paper used SBAS-InSAR technique to analyze land subsidence in Tianjin using 36-scence Sentinel-1A data. The average subsidence rate and phase deformation information during the period from 2015 to 2018 in study area were obtained. Compared with the previous research results and the leveling data in the study area, the results prove the reliability of the research using SBAS-InSAR technique. Based on the SBAS-InSAR inversion results in study area, it is concluded that obvious uneven settlement was detected in Tianjin from 2015 to 2018. The settlement center of Xiqing District tends to extend westward. The settlement of Yuzhangbao and Yuanjiabao villages in Wangqingtuo Town is the most obvious. The maximum average settlement rate in the settlement center exceeds $75 \mathrm{~mm} / \mathrm{a}$, and the maximum cumulative settlement reaches $190 \mathrm{~mm}$; overexploitation of groundwater and urbanization are the main factors affecting the surface deformation in Tianjin area, which also lead to the increasing range and extent of land subsidence in Tianjin. 


\section{ACKNOWLEDGEMENTS}

This work was supported by the National Natural Science Foundation of China (Grant Nos.41461089 and 41604019); the Guangxi Natural Science Foundation Project (Grant No. 2018GXNSFBA050006); the Key Laboratory of Geospace Environment and Geodesy, Ministry of Education, Wuhan University (Grant No. 18-01-01); the Guangxi Science and Technology Plan Project (Grant No. GUIKE AD19110107); the Wuhan Science and Technology Plan Project (Grant No. 2019010702011314); the Guangxi Young and Middle-aged Teacher Basic Ability Improvement Project (Grant No. 2018KY0247); the Guangxi Spatial Information Key Laboratory of Surveying and Mapping (Grant Nos. 16-380-2522 and 15-140-07-34). The authors wish to the European Space Agency (ESA) for providing Sentinel-1A satellite data and precise orbital ephemeris parameters (AUX_POEORB, POD Precise Orbit Ephemerides), National Aeronautics and Space Administration (NASA) for providing DEM data (SrtmV4 DEM).

\section{REFERENCES}

Amelung F, Galloway D L, Bell J W, et al, 1999. Sensing the ups and downs of Las Vegas: InSAR reveals structural control of land subsidence and aquifer-system deformation. Geology, 27(6): 483-486.

Berardino P, Fornaro G, LanariR, et al, 2002. A new algorithm for surface deformation monitoring based on small baseline differential SAR interferograms. IEEE Transactions on Geoscience and Remote Sensing, 40(11): 2375-2382.

Dong S. C., Yin H. W., Yao S. P., et al, 2013, Detecting surface subsidence in coal mining area based on DInSAR technique. Journal of Earth Science, 24(3): 449-456.

Gao E. T., Fan D. L., Fu B. L., et al, 2019. Land Subsidence Monitoring of Nanjing Area Based on PS-InSAR and SBAS Technology. Journal of Geodesy and Geodynamics, 39(2): 158163.

Guo J. M., Hu J. Y., Li B.,et al, 2017. Land subsidence in Tianjin for 2015 to 2016 revealed by the analysis of Sentinel-1A with SBAS-InSAR. Remote Sensing Technology and Application, 11(2), 026-024.

Li D, Yang B, Chen C., 2018. Obtaining Coseismic Deformation Field of Jiuzhai Earthquake with Sentinel-1A. Remote Sensing Technology and Application, 33(6): 11411148 .

Ruiz-Constán A, Ruiz-Armenteros AM, Lamas-Fernández F, et al, 2016, Multi-temporal InSAR evidence of ground subsidence induced by groundwater withdrawal: the Montellano aquifer (SW Spain), Environ. Earth Sci. 75(3): 1-16.

Sun X. P., Lu X. Y., Wen X. H., et al, 2016. Monitoring of ground subsidence in Chengdu Plain using SBAS-InSAR. Remote Sensing for Land and Resources, 28(3): 123-129.

Wu Y., Wang Y. J., Yan S. Y., et al, 2017. Ground subsidence monitoring in water exploitation area based on time series InSAR and GIS. Journal of Guilin University of Technology, 37 (4): 635-640.
Yin H. J., Zhu J. J., Li Z. W., et al, 2011. Ground Subsidence Monitoring in Mining Area Using DInSAR SBAS Algorithm. Acta Geodaetica et Cartographica Sinica, 40(1): 52-58.

Zhang Y. M., Wang P., Luo X., et al, 2017. Monitoring Xi' an Land Subsidence Using Sentinel-1A Images and SBAS-InSAR Technology. Bulletin of Surveying, (4): 93-97.

Zhao C. Y., Zhang Q., Ding X. L., et al, 2009. Monitoring of land subsidence and ground fissures in Xian, China 2005 2006: mapped by SAR interferometry. Environmental Geology, 58(7).

Zhou L., Guo J. M., Li X., et al, 2016. Monitoring and Analyzing on Ground Settlement in Beijing Area Based on SBAS-InSAR. Journal of Geodesy and Geodynamics, 36(9): 793-797. 